\title{
Total Phenolic Contents and Antioxidant Properties of Pulp and Skin of Prickly Pear (Opuntia ficus indica) Fruits: Application on Juice and Jam
}

\author{
Areeg S. Aly ${ }^{1}$, Ragaa A. Sadeek ${ }^{1}$ and Hussein. A. Abd El-aal ${ }^{2}$
}

${ }^{1}$ Department of Home Economic, Faculty of Specific Education, Minia University, El- Minia, Egypt

${ }^{2}$ Department of Food Science, Faculty of Agriculture, Minia University, El-Minia, Egypt

\section{Abstract:}

7 he nutritional and health-promoting properties of prickly pear fruit has attracted attention and can may contribute to their increased consumption in the future being rich in bioactive compounds (polyphenols and ascorbic acid).

Skin considers the major by-product of the fruit. The main objective of the study was to evaluate the bioactive compounds content, antioxidant activity and sensory quality of prickly pear (pulp, skin and whole fruit) juice and jam. Proximate composition, $\mathrm{pH}$, acidity, total phenols, total flavonoids, antioxidant activity using (DPPH) and sensory evaluation of pulp, skin, whole fruit juice and jam were evaluated. The data revealed that the moisture content ranged from $90.01 \% \pm 0.13$ to $90.98 \% \pm 0.18$ for prickly pear skin juice and pulp juice, respectively. Prickly pear skin juice and jam had the highest values of ash $1.347 \pm 0.02$ and $1.00 \pm 0.03$, respectively. Total soluble solid of juice and jam ranged from $8.50 \%$ to $8.90 \%$ and $68.00 \%$ to $67.5 \%$ for juice and jam, respectively. The $\mathrm{pH}$ values of juice $(5.68-5.78)$ were higher than that of jam (4.05 -4.34). Prickly pear skin juice and jam significantly $(\mathrm{P} \leq 0.05)$ had the highest values of total flavonoids and total phenols which recorded (379.67 \pm 9.5 and $204.03 \pm 5.10 \mathrm{mg} / 100 \mathrm{~g})$ and $(152.08$ \pm 5.93 and $151.33 \pm 1.70 \mathrm{mg} / 100 \mathrm{~g}$ ), respectively and subsequently high significantly $(\mathrm{P} \leq 0.05)$ values of antioxidant activity using DPPH. Jam processed from skin and whole fruit significantly $(\mathrm{P} \leq 0.05)$ had the highest sensory scores. In conclusion, prickly pear pulp, skin and whole fruit juice can be used successful for producing jam content bioactive compounds and antioxidant activity with acceptable sensory characteristics.

Key Words: Prickly pear, juice, jam, chemical composition, acidity, total phenols, antioxidant activity, DPPH.

\section{Introduction}

Prickly pear (Opuntia ficus-indica) is a tree originating in Mexico and yields an edible fruit, belongs to the family Cactaceae. It is widely distributed in Latin America, South Africa and the Mediterranean area including Egypt. The fruit is usually consumed fresh, during the ripening 
period, July-October and well appreciated by consumers because they are flavorsome good (Albano et al., 2015; Elhassaneen et al., 2016 and Khatabi et al., 2016 ). The prickly pear fruit also called cactus pear fruit grow in areas with poor soil, extremely high daytime temperatures and limited water supplies, is an oval elongated berry with enveloped by peel (skin) with thorns, pulp fruit have number of seed and pulp of fruit is fleshy edible and a juicy. Fruit have a different color such as green, canary yellow, lemon yellow, red, cherry-red or purple hues. These are the betalains present in the epidermis and the pulp of the prickly pear confers on it its color varying from yellow to purple (Stintzing et al., 2001; ElMostafa et al., 2014 and Du Toit et al., 2018).

Prickly pear is considering a functional food because it is an important source of nutrients such as fibers, amino acids vitamin E, ascorbic acid, carotenoids sugars, organic acids, minerals and seeds (oil composition) (Stintzing et al., 2003; El-Mostafa et al., 2014; Anwar and Sallam, 2016 and Elhassaneen $\boldsymbol{e t}$ al., 2016). Several studies that have been investigated the composition of pulp in the cactus pear fruit and considered as a good source of minerals, in particular phosphorous, calcium and magnesium make cactus pear juice useful in prevention of osteoporosis and cramps(Abou-Zaid et al., 2013 and Cota-Sanchez, 2016).

Prickly pear fruit juice is a source of betaxanthin pigments which can be used as water-soluble natural colorants in foods and rich in phenolic compounds, that consumption may play a vital role in health through the regulation of metabolism, weight, chronic disease (Maataoui and Hilali, 2004; Cory et al., 2018 and Fernández-López et al., 2018). Betalains and polyphenols are antioxidants that contribute to nutritional prickly pears quality and to their products of transformation. Another important antioxidants in prickly pear fruits include pectin and flavonoids including kaempferol, quercetin (Anwar and Sallam, 2016, Cota-Sanchez, 2016 and Khatabi et al., 2016).

Notably, natural cactus pear fruit compounds and derivatives have biologically activities such as antiulcerogenic, anticancer, antimicrobial, neuroprotective, hepatoprotective, anti-inflammatory, antioxidant properties that may help in preventing chronic pathologies such as diabetes 
(Madrigal-Santillán et al., 2013, El-Mostafa et al., 2014 and Albano et al.,2015) and also in many countries over the world used it for treating number of diseases such as hypertension, burns and indigestion Prickly pear is an important source of bioactive compounds, where it is considered an important source of bioactive compounds ( Elhassaneen et al., 2016).

In the food industry, there is a continuous search for ingredients that might provide advantageous properties to food products, either considering their nutritional value or bioactivity (Chahdoura et al., 2017). Prickly pear fruit is consumed directly or after being processed to products such as fruit purees or jams (Javanmard and Endan, 2010). Low acidity and fairly high sugar content in the fruit make it very sweet and delicious and can be prepared recipes range from appetizers desserts, drinks from prickly pear (Abou-Zaid et al., (2013).

Jam is a semi-solid mixture, prepared by cooking the fruit soft tissue, jam production requires right proportion of the right ingredients to get the desired result, which are; sugar, acid and pectin to a balance thick. Jam should include more than $68.5 \%$ total soluble solids (TSS) plus at least $45 \%$ fruit. As mentioned, the codex alimentations commission identify that the finished jam be supposed to contain more than 65\% TSS. In jam production, pectin can be obtained from fruit peels like orange which increases the dietary fiber of the end product and also reduces blood sugar when consume (Gimenez et al., 2001; Ozdogan and Yilmaz, 2011 and Awolu et al., 2018). Furthermore, this fruit is usually consumed as a fresh fruit or juice and to a lesser extent as jams (Madrigal-Santillán et al., 2013). Therefore, the objective of this study was to take advantage and integrate whole fruit of prickly pear to produce jam product to be acceptable in nutritional quality and sensory attributes.

\section{Materials and Methods Prickly Pear Fruit Samples}

Fresh fruits of prickly pear were obtained from local market at Minia Governorate, Egypt. After washed with running water well and remove thorns with knife and manual separation of the skin from the pulp, portioned and stored at $-20^{\circ}$ until analysis and juice and jam preparation. 
$\mathbf{T}_{1}=50 \%$ prickly pear pulp (PPP) juice $+50 \%$ sugar $+0.3 \%$ pectin (from juice weight $)+0.3 \%$ citric acid (from sugar weight).

$\mathbf{T}_{\mathbf{2}}=50 \%$ prickly pear skin (PPS) juice $+50 \%$ sugar $+0.3 \%$ pectin (from juice weight $)+0.3 \%$ citric acid (from sugar weight).

$\mathbf{T}_{3}=50 \%$ whole prickly pear pulp (PPW) juice $+50 \%$ sugar $+0.3 \%$ pectin (from juice weight $)+0.3 \%$ citric acid ( from sugar weight).
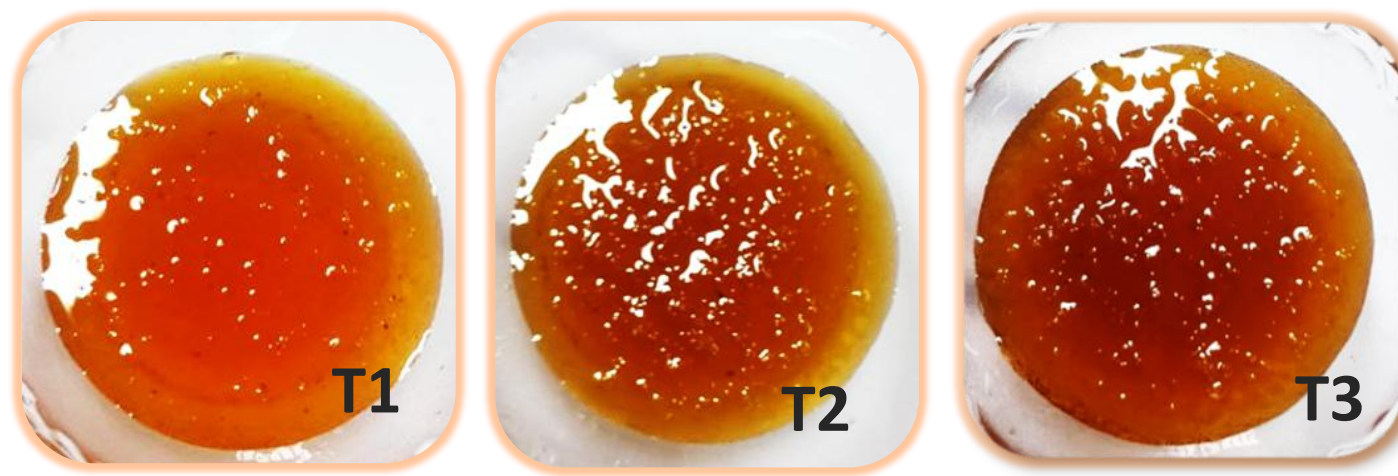

Figure (3): Prickly pear jams

\section{Proximate chemical composition of Prickly pears}

Moisture and ash were determined according to the methods of AOAC, (2000). Total carbohydrates were determined by using phenol sulphuric acid according to the method of (Dubois $\boldsymbol{e t}$ al., 1956 and Krishnaveni $\boldsymbol{e t}$ al., 1984). Total soluble solids (TSS \%) was determined using refract meter (Jon way, UK). $\mathrm{pH}$ value was determined by using $\mathrm{pH}$-meter with glass electrode (model 41250, ICM, OR, USA) according to the method of (Peter, 2013). Total acidity was determined according to (AOAC, 2005) and results were expressed as g citric acid per 100g. Ascorbic acid was determined using the official titrimetric method (AOAC, 2000), and expressed as $\mathrm{mg} / 100 \mathrm{~g}$ fresh sample

\section{Preparation of Prickly pears phenolic extract}

Prickly pears phenolic extract was prepared as follow: $10 \mathrm{~g}$ of juice or jam was extracted with $95 \%$ ethanol at a ratio of 1part of pepper fruit: 3parts of $95 \%$ ethanol W/V using a Vortex, Model B-4, Waring products Co., Winsted CONN. The extraction was filtered through filter paper No. 1 with Buchner funnel and the residue was re-extracted two

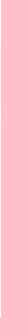


times under the same conditions. The combined of filtrate for each sample was transferred to $50 \mathrm{ml}$ volumetric flask and completed with $95 \%$ ethanol. All extracts were kept in brown bottle at $4{ }^{\circ} \mathrm{C}$ and used for evaluation of total phenol, flavonoid and antioxidant activity.

\section{Determination of total phenolic}

Analysis was performed by adding $3.5 \mathrm{ml}$ of deionized water, $50 \mu \mathrm{L}$ of sample extract and Folin-Ciocalteu reagent and $300 \mu \mathrm{L}$ of sodium carbonate $20 \%$ to cuvette. The reaction was left for 15 minutes and then the absorbance was measured in triplicate at $730 \mathrm{~nm}$ using a UV/VIS spectrophotometer (Shimadzu, Kyoto, Japan). The blank consisted of all reagents excluding the sample extract. A standard curve was fashioned using Tannic acid at concentrations of $0.2,0.4,0.6,0.8$, and $1.0 \mathrm{mg} / \mathrm{mL}$ diluted in ethanol. Total phenolic concentration was expressed as $\mathrm{mg}$ of tannic acid equivalents via the standard curve (Singleton and Rossi, 1965).

\section{Determination of total flavonoids}

The total flavonoids content of pepper extract was determined use a colorimetric method described by (Zhishen et al., 1999). A $0.5 \mathrm{ml}$ of pepper sample extract was mixed with $2 \mathrm{~mL}$ of distilled water and subsequently with $150 \mu \mathrm{L}$ of a $5 \%$ NaNO2 solution. After 6 min, 150 $\mu \mathrm{L}$ of a 10\% AlCL3 solution was added and allowed to stand for 6 min and then 2 $\mathrm{mL}$ of $4 \% \mathrm{NaOH}$ solution was added to the mixture. Immediately, water was added to bring the final volume to $5 \mathrm{~mL}$, and then the mixture was thoroughly mixed and allowed to stand for another $15 \mathrm{~min}$. Absorbance of the mixture was determined at $510 \mathrm{~nm}$ versus prepared blank. Quercetin was used as standard compound for the quantification of total flavonoids. All values were expressed as milligrams of quercetin equal per 100 gram of fresh pepper. Data were reported as means (SD) for three replications.

\section{Determination of total antioxidant activity}

Total antioxidant activity was determined following the method of ( $\mathbf{S u}$ and Silva, 2006). A $100 \mu \mathrm{M}$ 2.2-diphenyl-1-picrylhydrazyl (DPPH) was prepared by dilution of $32 \mathrm{mg}$ of DPPH with $800 \mathrm{~mL}$ of ethanol. $500 \mu \mathrm{L}$ of 


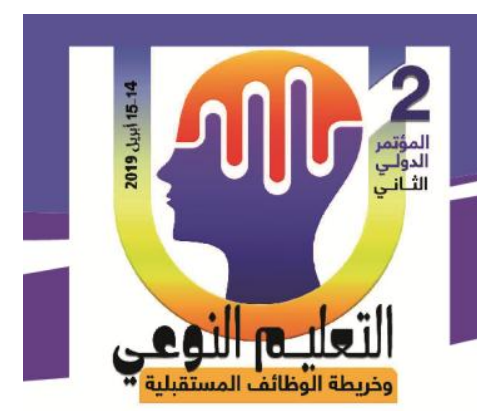

sample extract was added to $3.0 \mathrm{~mL}$ of DPPH solution in a cuvette. After 10 minutes the absorbance of the reaction mixture was measured in triplicate at $517 \mathrm{~nm}$ in a spectrophotometer. The control solution was prepared by adding $500 \mu \mathrm{L}$ of ethanol to the DPPH solution and ethanol was used as blank. The antioxidant activity (\%) was determined by the following formula:

Activity $(\%)=\left[\left(\mathrm{Abs}_{\text {control }}-\mathrm{Abs}_{\text {sample }}\right) / \mathrm{Abs}_{\text {control }}\right] \times 100$.

Where Abs is the absorbance determined at $517 \mathrm{~nm}$. A $1.4 \mathrm{mg} / \mathrm{mL}$ quercetin dehydrate standard was prepared for comparison.

\section{Sensory evaluation of jam}

Jam samples were presented with bread present from to thirty panelists who were asked to rate each sensory attribute. Were asked to rate the samples parameters flavor, colour, taste and overall acceptability on a 10point hedonic scale and indicate their observations.

\section{Statistical analysis}

Data were analyzed with GLM (General leLLinear Model) program using statistical analysis system (SAS, 2003). Mean values were compared by Duncan's Multiple Test.

\section{Results and Discussion}

\section{Proximate chemical composition of prickly pear (juice and jam)}

Data of proximate composition of prickly pear (juice and jam) is presented in Table (1). Moisture has important effect on the shelf life of products (Eke-Ejiofor and Owuno, 2013). So we determine the moisture in prickly pear (juice and jam) and found a significance $(\mathrm{p} \leq 0.05)$ difference between the prickly pear juice sample and the prickly pear jam (pulp, skin and whole fruit). It was the moisture content was high in juice than the jam product which range from 90.01 to $31.04 \%$ respectively. Result came close to the results from (Abou-Zaid et al., 2013) who reported that moisture in prickly pear juice was $(87.72 \%)$. The decrease in moisture is expected because of the heating process during producing jam which leads to water removal and thus concentration of food nutrients (Saka et al., 2007 and Awolu et al., 2018). 
Table (1): Proximate composition in prickly pear (juice and jam)

\begin{tabular}{l|c|c|c|c|c}
\hline \multicolumn{2}{c|}{ Samples } & Moisture (\%) & Ash (\%) & Carbohydrate (\%) & $\begin{array}{c}\text { Total soluble } \\
\text { solids (\%) }\end{array}$ \\
\hline \multirow{3}{*}{$\leftrightarrows$} & $($ PPP) & $90.98 \pm 0.18^{\mathrm{a}}$ & $0.297 \pm 0.01^{\mathrm{e}}$ & $8.39 \pm 0.28^{\mathrm{b}}$ & $8.5^{\mathrm{e}}$ \\
\cline { 2 - 6 } & $($ PPS) & $90.01 \pm 0.13^{\mathrm{b}}$ & $1.347 \pm 0.02^{\mathrm{a}}$ & $8.87 \pm 0.34^{\mathrm{b}}$ & $8.9^{\mathrm{c}}$ \\
\cline { 2 - 6 } & $($ PPW) & $90.53 \pm 0.05^{\mathrm{a}}$ & $0.713 \pm 0.02^{\mathrm{c}}$ & $8.67 \pm 0.04^{\mathrm{b}}$ & $8.8^{\mathrm{d}}$ \\
\hline \multirow{4}{*}{} & $($ PPP) & $31.95 \pm 0.39^{\mathrm{d}}$ & $0.29 \pm 0.01^{\mathrm{e}}$ & $67.00 \pm 0.81^{\mathrm{a}}$ & $67.5^{\mathrm{b}}$ \\
\cline { 2 - 6 } & $($ PPS) & $31.04 \pm 0.66^{\mathrm{e}}$ & $1.00 \pm 0.03^{\mathrm{b}}$ & $67.92 \pm 0.94^{\mathrm{a}}$ & $68^{\mathrm{a}}$ \\
\cline { 2 - 6 } & $($ PPW) & $32.93 \pm 0.11^{\mathrm{c}}$ & $0.453 \pm 0.01^{\mathrm{d}}$ & $67.33 \pm 1.08^{\mathrm{a}}$ & $67.9^{\mathrm{a}}$ \\
\hline
\end{tabular}

*PPP, prickly pear pulp; PPS, prickly pear skin; PPW, prickly pear whole fruit. Mean value followed by different letter in the same column are significantly different at $\mathrm{P} \leq 0.05$

Data indicated that the juice sample of prickly pear contain ash ranged from 0.297 to $0.1347 \%$, while in jam sample ranged from 0.29 to $1.00 \%$; prickly pear skin had the highest ash content in the both (juice and jam). Several studies have documented that cactus have the plenty of vitamins and minerals (Stintzing et al., 2003). The results also show high amount of T. carbohydrate content in prickly pear skin (juice and jam). These result agreed with the results mentioned by (El-Mostafa et al., 2014) who reported that the prickly pear a good source of fiber and sugar.

Total soluble solids (TSS) is one of the most important characteristics for the fresh fruit which measures the sugar content and it is a different chemical substances found in soluble form (Oelofse et al., 2006 and Kanwal et al., 2017). Data in Table (1) shown the mean values of TSS recorded of PP juice were $(8.5 \%, 8.9 \%$ and $8.8 \%$ ) for prickly pear (pulp, skin and whole fruit) respectively. There was a significance $(p \leq 0.05)$ difference in total soluble solids between the prickly pear juice sample and the prickly pear jam (pulp, skin and whole fruit), the TSS values for prickly pear (pulp, skin and whole fruit) jam were (67.5, 68 and 67.9) respectively. The increasing in TSS may be due to acid hydrolysis of polysaccharides especially pectin and gums (Kanwal et al., 2017). From the results explained, it can be concluded that the incorporation of skin in prickly pear jam can improve the nutritional quality.

\section{Physicochemical properties of prickly pear (juice and jam)}


Results in Table (2) are shown that the antioxidants compounds in prickly pear (juice and jam) which that include ascorbic acid, total phenols and another important constituent in prickly pear is flavonoids. Data showed that flavonoids content, ascorbic acid, total phenols and antioxidant activity in prickly pear juice of was higher than jam. Data in Table (2) showed that vitamin $\mathrm{C}$ content in prickly pear juice (pulp, skin and whole fruit) was $(28.86,3.31$ and $15.60 \mathrm{mg} / 100 \mathrm{~g})$ respectively. These results are agreed with the results mentioned by (Stintzing $\boldsymbol{e t}$ al., 2001) who decided that, the cactus pear fruit has content vitamin $C$ about $(18-23 \mathrm{mg} / 100 \mathrm{~g}$ fresh weight) and with the results reported by (Feugang et al., 2006) who confirmed that vitamin $\mathrm{C}$, is the third major vitamin in prickly pears fruits and was found in fruit pulp ranged from $12-81 \mathrm{mg} / 100 \mathrm{~g}$ fresh weight. On other hand results shows significant decrease in ascorbic acid content of prickly pear jam (pulp, skin and whole fruit) was (3.19, 0.16 and 1.64 $\mathrm{mg} / 100 \mathrm{~g}$ ) respectively, this is due to exposed fruit to more severe heat treatment during manufacturing to jam and the cooking time which considered as important factors effect on the loss rate of vitamin $\mathrm{C}$. In this context, Jawaheer et $\boldsymbol{a l}$., (2003) confirmed that when temperature rise of $10 \circ \mathrm{C}$ usually increases the rate of degradation and the longer the processing time, the higher the increase in ascorbic acid loss because ascorbic acid is water soluble and unstable to highly heat.

Table (2): Content of vitamin $C$, flavonoids, total polyphenols and antioxidant activity in prickly pear (juice and jam)

\begin{tabular}{|c|c|c|c|c|c|}
\hline \multicolumn{2}{|c|}{ Samples } & Ascorbic acid & Flavonoids & Total polyphenols & Antioxidant \\
\hline \multirow{3}{*}{.$\stackrel{\mathscr{U}}{\Xi}$} & ( PPP) & $28.86 \pm 1.46^{\mathrm{a}}$ & $328.3 \pm 4.9^{b}$ & $151.33 \pm 4.19^{c}$ & $31.93 \pm 0.56$ \\
\hline & (PPS) & $3.31 \pm 0.72^{c}$ & $379.67 \pm 9.5^{\mathrm{a}}$ & $204.03 \pm 5.10^{\mathrm{a}}$ & $28.23 \pm 0.17$ \\
\hline & ( PPW) & $15.60 \pm 1.34^{b}$ & $341.67 \pm 4.5^{b}$ & $194.33 \pm 2.05^{b}$ & $30.33 \pm 0.21$ \\
\hline \multirow{3}{*}{ ే } & ( PPP) & $3.19 \pm 0.29^{c}$ & $97.26 \pm 3.01^{\mathrm{e}}$ & $94.06 \pm 4.17^{\mathrm{d}}$ & $27.63 \pm 0.24$ \\
\hline & (PPS) & $0.16 \pm 0.03^{\mathrm{d}}$ & $152.08 \pm 5.93^{\mathrm{c}}$ & $151.33 \pm 1.70^{c}$ & $26.47 \pm 0.26$ \\
\hline & ( PPW) & $1.64 \pm 0.51^{\mathrm{d}}$ & $135.33 \pm 4.18^{\mathrm{d}}$ & $146.67 \pm 5.18^{c}$ & $26.75 \pm 0.33$ \\
\hline
\end{tabular}
letter in the same column are significantly different at $\mathrm{P} \leq 0.05$

Recently, increase interest of phenolic compounds because the potential health benefits of these compounds which antioxidant and anticancer, that 


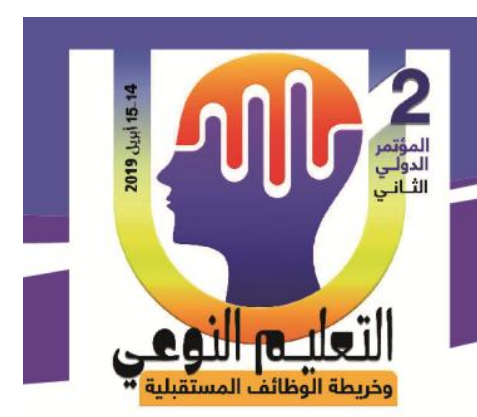

may help to prevent chronic disease. The total phenolic content and the antioxidant activity of the prickly pear (juice and jam) were evaluated. Data in Table (2) shows significant increase in total polyphenol and flavonoid content in prickly pear skin than prickly pear pulp and prickly pear whole fruit in (juice and jam). These results agree with data reported by (ElMostafa et al., 2014) who confirmed that all parts of the cactus plant are rich in members of the polyphenol family such as various flavonoids and phenolic acids.

Flavonoid content in prickly pear juice (pulp, skin and whole fruit) was (328.3, 379.67 and $341.67 \mathrm{mg} / 100 \mathrm{~g}$ ) respectively. While it content in prickly pear jam (pulp, skin and whole fruit) it was (97.26, 152.08 and $135.33 \mathrm{mg} / 100 \mathrm{~g}$ ) respectively.

Data present in the same Table explained that the polyphenol content in prickly pear juice (pulp, skin and whole fruit) was (151.33, 204.03 and $194.33 \mathrm{mg} / 100 \mathrm{~g}$ ) respectively. The result is agreed with data mentioned by Khatabi et al., (2016), who reported that that prickly pears whole fruit (pulp and seeds) contain a quantity of polyphenols. But there was occur decreased in the polyphenol content of prickly pear jam (pulp, skin and whole fruit) was dropped percentage $(37.84 \%, 25.82 \%$ and $24.53 \%$ ) respectively about prickly pear juice may be due to increase expose of temperature during jam manufacturing. Moldovan et al., (2016), who studied the influence of the temperature on the phenol content and reached that phenol content was stable at temperatures up to $22{ }^{\circ} \mathrm{C}$ but with increase temperature increase rate constants of the degradation.

The data revealed the value of antioxidant activity in prickly pear pulp was higher than prickly pear skin and whole fruit; the reason can be to that pulp contains seeds that are rich in polyphenols. Several studies have documented the abundance the nutrients and antioxidant compounds (ascorbic acid, carotenoids, phenols, flavonoids and betacyanin) in prickly pear fruit (El -Mostafa $\boldsymbol{e t}$ al., 2014). Many studies explained that the health beneficial effects of in prickly pears fruits polyphenols and flavonoids might be it plays a higher role in antioxidant and radical scavenging activities (Galati et al., 2003, Tesoriere et al., 2004 and Khan et al., 2000). On other hand occur reduce in the value of antioxidant activity in prickly pear jam that may be due to loss of ascorbic acid and flavonoid. Also these results could be explained by a possible transformation in the phenolic compounds (Corrêa et al., 2014). 
Chemical properties of prickly pear (juice and jam)

Table (3): Chemical properties ( $\mathrm{pH}$, acidity and density) of prickly pear (juice and jam)

\begin{tabular}{c|l|c|c|c}
\hline \multicolumn{2}{c|}{ Samples } & pH value & Acidity (\%) & Density \\
\hline \multirow{3}{*}{$\Xi$} & $($ PPP) & $5.78^{\mathrm{a}}$ & $0.128^{\mathrm{d}}$ & $1.353^{\mathrm{e}}$ \\
\cline { 2 - 5 } & $(\mathrm{PPS})$ & $5.68^{\mathrm{c}}$ & $0.132^{\mathrm{d}}$ & $1.354^{\mathrm{d}}$ \\
\cline { 2 - 5 } & $(\mathrm{PPW})$ & $5.72^{\mathrm{b}}$ & $0.108^{\mathrm{e}}$ & $1.352^{\mathrm{f}}$ \\
\hline \multirow{4}{*}{$\Xi$} & $(\mathrm{PPP})$ & $4.05^{\mathrm{f}}$ & $0.162^{\mathrm{c}}$ & $1.459^{\mathrm{c}}$ \\
\cline { 2 - 5 }$\leftrightarrows$ & $(\mathrm{PPS})$ & $4.34^{\mathrm{d}}$ & $0.202^{\mathrm{a}}$ & $1.461^{\mathrm{a}}$ \\
\cline { 2 - 5 } & $(\mathrm{PPW})$ & $4.09^{\mathrm{e}}$ & $0.189^{\mathrm{b}}$ & $1.460^{\mathrm{b}}$ \\
\hline
\end{tabular}

*PPP, prickly pear pulp; PPS, prickly pear skin; PPW, prickly pear whole fruit. Mean values followed by different letter in the same column are significantly different at $\mathrm{P} \leq 0.05$

The $\mathrm{pH}$ value in food and jam was considering an important factor for directly related to the free hydrogen ions (Kanwal et al., 2017). Data are present in Table (3) shown the lowest $\mathrm{pH}$ score was observed for prickly pear pulp jam was (4.05) and highest score was observed for prickly pear pulp juice was (5.78). These results we agreed well with data reported by (Feugang $\boldsymbol{e t}$ al., 2006) who found the $\mathrm{pH}$ values in cactus pear fruits ranging from 5.0 to 6.6 .

Statistical analysis revealed significant results in acidity among all samples. The acidity values recorded for prickly pear juice (pulp, skin and whole fruit) were $(0.128 \%, 0.132 \%$ and $0.108 \%)$ respectively. Data agreed well with result mentioned by Feugang et al., (2006) cactus pear fruits exhibit acidity of $0.03-0.12 \%$ and results were close to the results documented by Abou-Zaid et al., (2013) who found that the acidity content of the prickly pear juice was $(0.65 \%)$. While acidity values increase in prickly pear jam (pulp, skin and whole fruit) were $(0.162,0.202$ and 0.189 ) respectively. The increase in acidity value of jam may be due to the organic acids present naturally, degradation of polysaccharides and oxidation of reducing sugars or by break down of pectin in to pectenic acid (Kanwal et al., 2017). Data are present in Table (3) shown the lowest density was observed for prickly pear whole fruit juice was (1.352) and highest density was observed for prickly pear skin jam was (1.461). Garza and Ibarz, (2010) and Cepeda and Villaran, (1999), whom explained the density values were linearly correlated with soluble solids concentration and density of juices as functions of soluble solids content and temperature. 


\section{Sensory evaluation}

Sensory evaluation is considering as the quality parameters for the jam products (Hayes et al., 1998). So it was applied to 30 people to measurement the organoleptic attributes and acceptability of the jam products. In Table (4) are present comparative sensory evaluation of different products for prickly pear jam. Data revealed that evaluations for all samples don't have any significant differences in sensory evaluation with slightly differences in mean of scores. The mean score showed that prickly pear whole fruit jam was most acceptable from panelists and it is preferred, with considering all the points as colour, odor, taste, texture and overall acceptability followed by prickly pear skin. While prickly pear pulp jam was have lowest scored of the sensory characteristics. In general, the product presented good acceptability, because the overall liking mean scores obtained were between (8.97 and 9.13).

Table (4): Sensory test values of the prickly pear jam products

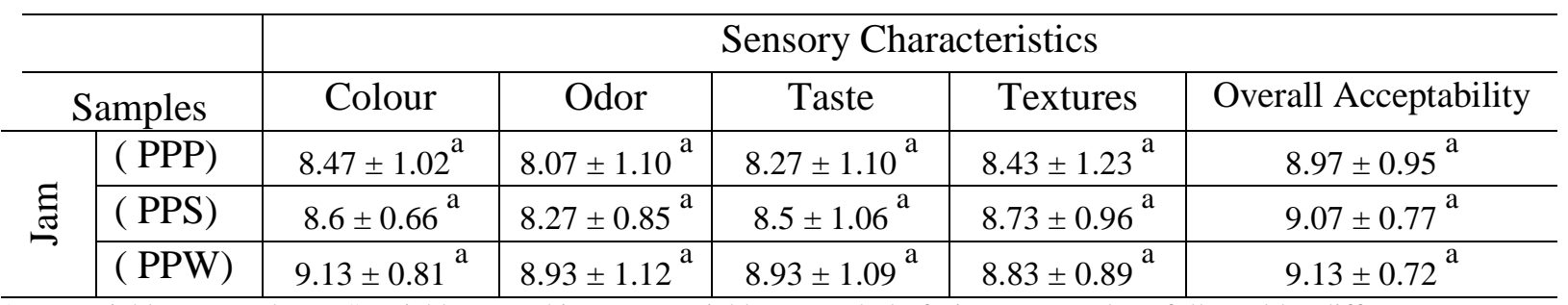

*PPP, prickly pear pulp; PPS, prickly pear skin; PPW, prickly pear whole fruit. Mean values followed by different letter in the same column are significantly different at $\mathrm{P} \leq 0.05$

\section{Conclusion}

Based on the findings that prickly pear skin which currently discarded as waste when blending with PP pulp can improving their products with vitamins, minerals and besides colour, flavour, taste and overall acceptability. So that highly recommended to take advantage and integrate the skin of prickly pear fruit to many product due to its nutritional value.

\section{References}

Abou-Zaid, A.; Nadia, I.; Ramadan, M.T. and Nadir, A.(2013). Quality evaluation of sheets, jam and juice from prickly pear and melon blends .Life Science Journal;10(2):200-208. 


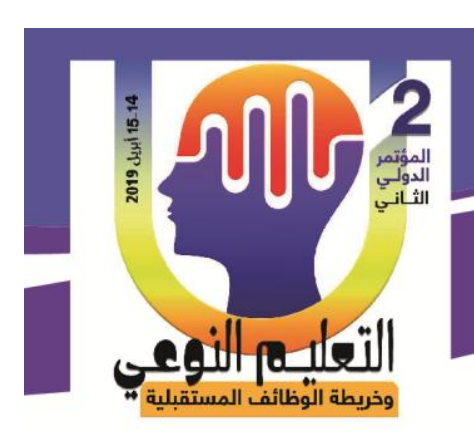

Albano, C.; Negro, C.; Tommasi, N.; Gerardi, C.; Mita, G.; Miceli, A.; De Bellis, L. and Blando, F.(2015). Betalains, Phenols and Antioxidant Capacity in Cactus Pear [Opuntia ficus-indica (L.) Mill.] Fruits from Apulia (South Italy) Genotypes. Antioxidants (Basel). 4(2): 269-280.

Anwar, M.M. and Sallam, E.M. (2016). Utilization of Prickly Pear Peels to Improve Quality of Pan Bread Arab Journal of Nuclear Science and Applications, 49 (2): 151-163.

A.O.A.C., (2000). Official methods of Analysis $17^{\text {th }}$ ed.; 106-250. Association of official Analytical Chemist. Washington. U.S.A.

AOAC (2005). Official Methods of Analysis of Association of Official Analytical Chemists. Published by the AOAC international $18^{\text {th }}$ Ed. Washington, D.C.

Awolu, O.O.; Okedele, G.O.; Ojewumi, M.E. and Oseyemi, F.G. (2018). Functional Jam Production from Blends of Banana, Pineapple and Watermelon Pulp. International Journal of Food Science and Biotechnology: 3(1): 7-14.

Cepeda, E.; Villaran, M.C.1999 Density and viscosity of Malus floribunda juice as a function of concentration and temperature.Journal of Food Engineering 41(2): 103-107.

Chahdoura, H.; Barreira, J.C.; Adouni, K.; Mhadhebi, L.; Calhelha, R.C.; Snoussi, M.; Majdoub, H.; Flamini, G.; Ferreira, I.C. and Achour, L.(2017).Bioactivity and chemical characterization of Opuntia macrorhiza Engelm. seed oil: potential food and pharmaceutical applications. Food Funct.8(8):2739-2747.

Corrêa, R.C.; Haminiuk, C.W.; Sora, G.T.; Bergamasco, R. and Vieira, A.M.(2014). Antioxidant and rheological properties of guava jam with added concentrated grape juice. J Sci Food Agric.15;94(1):146-52.

Cory, H.; Passarelli, S.; Szeto, J.;Tamez, M. and Mattei, J. (2018). The Role of Polyphenols in Human Health and Food Systems: A Mini-Review.Front. Nutr. 5:87.

Cota-Snchez, H.(2016).Nutritional Composition of the PricklyPear (Opuntia ficusindica) Fruit. CHAPTER 28., First Edition, 691-712.

Dubois, M.; Gilles, K. A.; Hamilton, J. K.; Rebers, P. A. and Smith, F. (1956). Analytical Chemistry 26, 350.

Du Toit, A.; De Wit,M. and Hugo, A.(2018). Cultivar and Harvest Month Influence the Nutrient Content of Opuntia spp. Cactus Pear Cladode Mucilage Extracts. Molecules. 23(4), 916.

Eke-Ejiofor, J. and Owuno, F. (2013). The Physico-chemical and Sensory Properties of Jackfruit (Artocarpus heterophilus) Jam. International Journal of Nutrition and Food Sciences. 2 (3):149-152. 


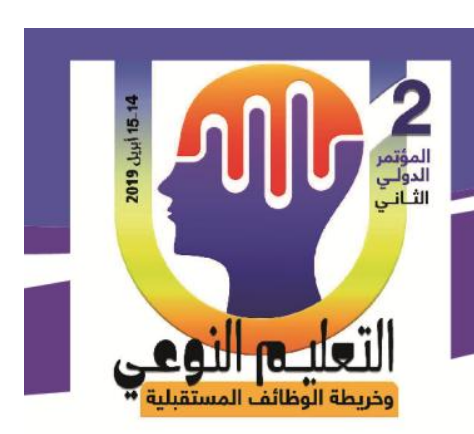

Maataoui, B.S. and Hilali, S., (2004). Composition physico-chimique dejus de deux types de fruits de figuier de Barbarie (Opuntia ficus indica) cultive's au Maroc. Rev. Biol. Biotechnol. 3 (2): 8-13.

Madrigal-Santillán, E.; García-Melo, F.; Morales-González, J.; Vázquez-Alvarado, P.; Muñoz-Juárez,S.; Zuñiga-PérezC.; Sumaya-Martínez, M.T.; Madrigal-Bujaidar, E.and Hernández-Ceruelos, A.(2013). Antioxidant and Anticlastogenic Capacity of Prickly Pear Juice Nutrients. 5(10), 4145-4158.

Mena, P.; Tassotti, M.; Andreu, L.; Nuncio-Jáuregui, N.; Legua, P.; Del Rio, D. and Hernández, F.(2018). Phytochemical characterization of different prickly pear (Opuntia ficus-indica (L.) Mill.) cultivars and botanical parts: UHPLC-ESI-MS ${ }^{\mathrm{n}}$ metabolomics profiles and their chemometric analysis. Food Res Int. 108:301308.

Moldovan, B.; Popa, A. and David1,L.(2016). Effects of storage temperature on the total phenolic content of Cornelian Cherry (Cornus mas L.) fruits extracts. Journal of Applied Botany and Food Quality 89, 208 - 211.

Oelofse, R.M.; Labuschagne, M.T. and Potgieter,J.P.(2006). Plant and fruit characteristics of cactus pear (Opuntia spp.) cultivars in SouthAfrica. Journal of the Science of Food and Agriculture. 86:1921-1925.

Ozdogan, F. and Yilmaz, E. (2011). Evaluation of green tomato jams prepared from two kinds of tomatoes. Akademik Gida. 9(2): 19-25.

Peter, R. (2013). "pH meters and their electrodes: calibration, maintenance and use". The Biomedical Scientist. April: 202-205.

Saka, J.; Rapp, I.; Akinnifesi, F.; Ndolo, V. and Mhango, J.(2007). Physicochemical and Organoleptic characteristics of Uapacakirkiana, Strychnoscocculoides, Adansoniadigitata and Mangiferiaindica fruit products. International Journal of Food Science and Technology, 42 (7): 836-841.

SAS Institute. (2003). SAS User's Guide: Statistics. SAS Institute, Cary, NC.

Singleton,V.L. ; Rossi, J. A. (1965). Colorimetry of total phenolics with phosphomolybdic phosphotungstic acid reagents. American Journal of Enology and Viticulture, 16: 144-158.

Stintzing, F.C. and Scheiber, A. and Carle, R. (2003). Evaluation of color properties and chemical quality parameters of cactus juices. Eur. Food Res.Technol. 216, 303311.

Stintzing, F.C.; Schieber, A. and Carle, R.(2001). Phytochemical and nutritional significance of cactus pear.Eur. Food Res. Technol. 212, 396-407.

SU, M. and SILVA, J.L. (2006). Antioxidant activity, anthocyanins, and phenolics of rabbiteye blueberry (Vaccinium ashei) by-products as affected by fermentation. Food Chem., 97, 447-451. 
Tesoriere, L.; Butera, D.; Pintaudi, A.; Allegra, M. and Alivrea, M. (2004). Supplementation with cactus pear (Opuntia ficus-indica) fruit decreases oxidative stress in healthy humans: a comparative study with vitamin C1-3. Am. J. Clin. Nutr.80: 391.

Zhishen, J. ; Mengcheng, T. and Jianming, W. (1999). The determination of flavonoid contents in mulberry and their scavenging effects on superoxide radicals. Food Chem. 64: 555-559. 
محتوى المركبات الفينولية الكلية والخصائص المضادة للأكسدة فى اللب والجلد لثمار التين الثوكى: تطبيقات على العصبر والمربى أريج سلامه على 1 ، رجاء أحمد صديق 1، حسين عبد الجليل عبد العال2 2 1- قسم الاقتصاد المنزلى، كلية التربية النوعية، جامعة المنيا، المنيا، مصر .

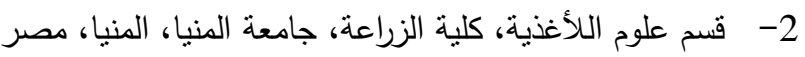

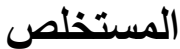

لقد جذبت الإنتباه الخصائص الغذائية والمعزّزة للصحة لفاكهة التنين الثوكي والتي يمكن

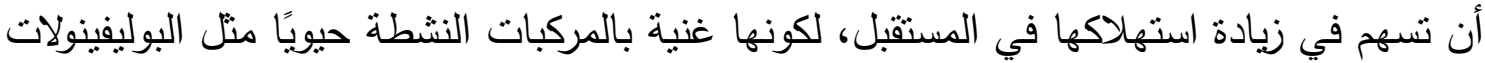

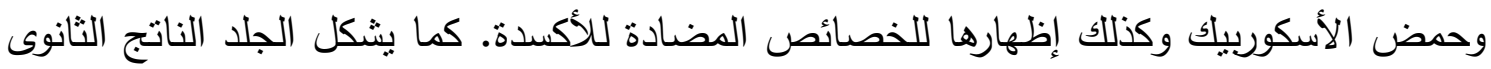
الرئيسى للثمرة. لذلك تهدف الدراسة الحالية الى تقييم المركبات النباتية النشطة حيويًا والخصائص

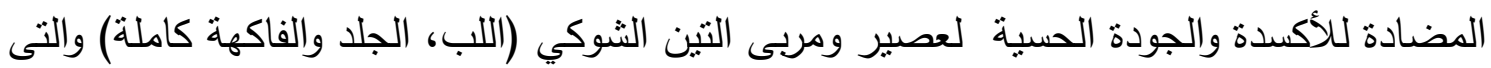

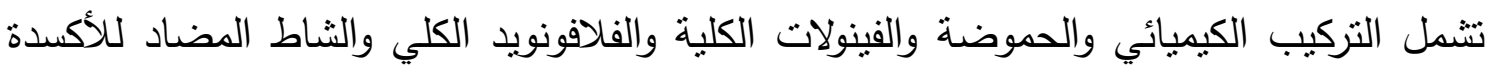

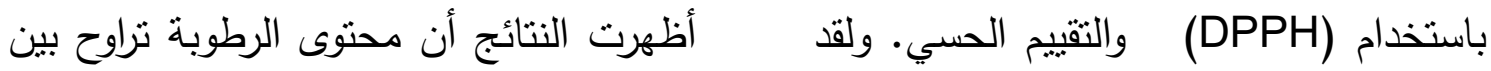

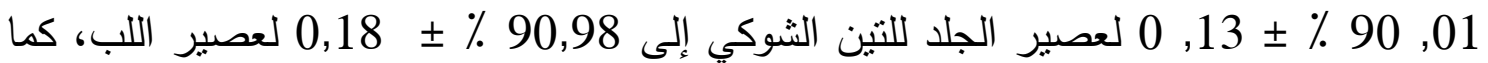

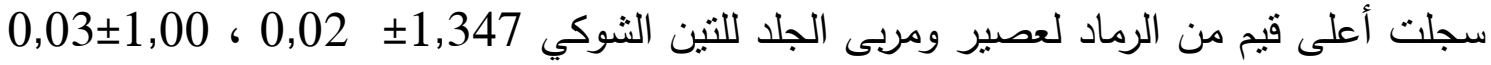

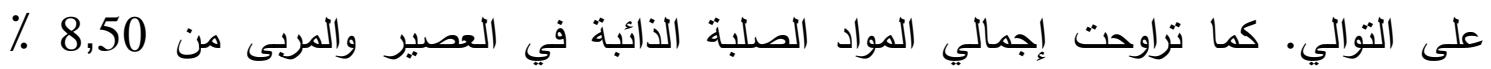

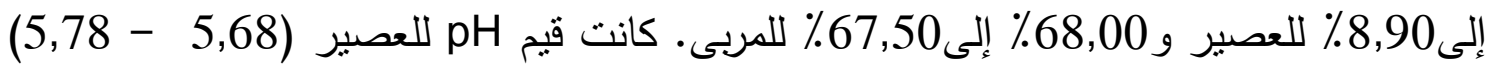
أعلى من المربى (4,05 ـ 4,34). كما سجل عصبر ومربى الجلد للتين الثوكي زيادة معنوية

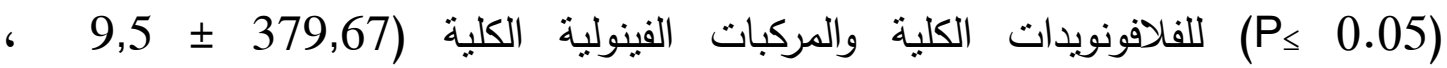

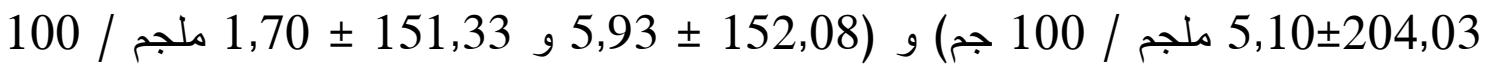
جم) على التوالي، و قابلها زيادة معنوية (PS 0.05) للنشاط المضاد للأكسدة باستخدام (DPPH)

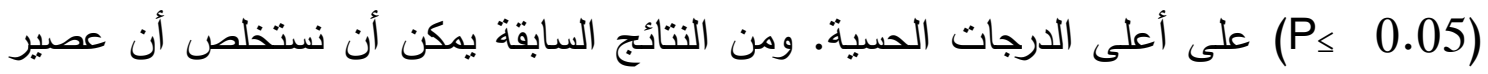

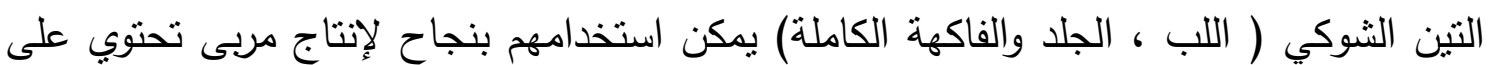
مضادات أكسدة ذات خصائص حسية مقبولة.

الكلمات المفتاحية: التين الثوكي، العصير، المربى، التركيب الكيميائى، الحموضة، الفينولات الكلية، الخصائص المضادة للأكسدة ، DPPH. 